\title{
BEHAVIOUR OF LAMINAR PREMIXED FLAME EXPOSED TO ALTERNATING ELECTRIC FIELD
}

\author{
Gaber M. Asar \\ Mechanical Power Engineering Department, Faculty of Engineering, Menoufia University, \\ Shebin El-kom, Egypt
}

\begin{abstract}
Combustion in the lean regime is an efficient way to improve combustion efficiency, minimize the emission of pollutants and fuel consumption. The drawback is that instabilities appear which may lead to extinction of the flame or blow-out. Among the different methods for improving the flame characteristics at lean mixtures is the application of electric field. The purpose of the present work is to elucidate experimentally the effect of electric field on laminar partial premixed flame characteristics. Temperature distribution inside flame, flame geometry (height and width), and reaction zone thickness were measured at different mixture strengths with and without the application of electric field and its orientation. The results showed that under the effect of electric field, the flame height decreases with enriching the mixture in the lean side, while the width increases with a higher rate. The minimum difference between change of the flame height and flame width occurs at slightly rich mixture of equivalence ratio equals to 1.03 . The reaction zone thickness increases as the electric field is applied on the flame. The change in temperature inside the flame when the electric field is applied is marginal. Electric field makes flame stabilized until reaching a lean flammability limit $(\phi=0.67)$. Horizontal electrodes give a little effect on the flame characteristics represented by temperature.
\end{abstract}

Keywords: Premixed Flame, Electric Field, Reaction Zone, Alternating Current, Gaseous Fuels

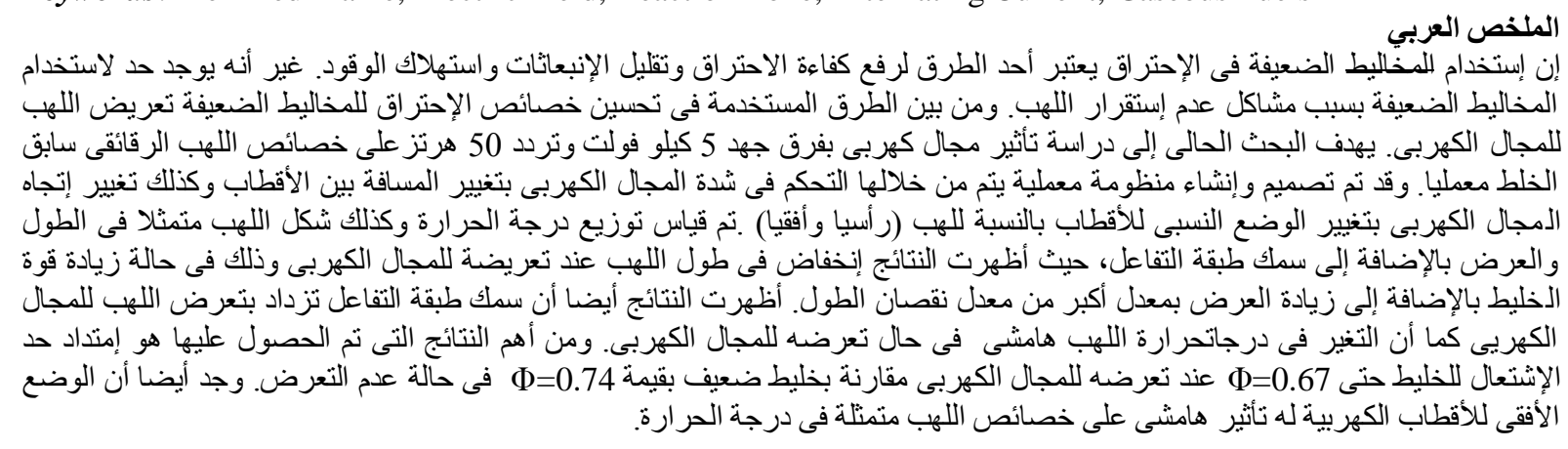

\section{NOMENCLATURE}

$\begin{array}{ll}\text { AC } & \text { Alternating current } \\ \text { DC } & \text { Direct current } \\ \mathrm{D} & \text { Burner diameter }(\mathrm{mm}) \\ \mathrm{d}_{\mathrm{o}} & \text { Flame width without electric field }(\mathrm{mm}) \\ \mathrm{d}_{\mathrm{e}} & \text { Flame width with electric field }(\mathrm{mm}) \\ \mathrm{LPG} & \text { Liquid petroleum gas } \\ \mathrm{L} & \text { Total flame length }(\mathrm{mm}) \\ \mathrm{l} & \text { premixed flame length }(\mathrm{mm}) \\ \mathrm{l}_{\mathrm{o}} & \text { Flame length without electric field }(\mathrm{mm}) \\ \mathrm{l}_{\mathrm{e}} & \text { Flame length with electric field }(\mathrm{mm}) \\ \mathrm{MP} & \text { Mega pixel } \\ \phi & \text { Equivalence ratio }\end{array}$




\section{INTRODUCTION}

Application of the electric field is important in many aspects of research and practical applications. Among important applications is the combustion process of hydrocarbon fuel and its interrelation with electric field. Over the last years an increasing interest to an ability to provide different methods of combustion control with application of external forces (electric, magnetic) to the flame has been observed. Many researches have taken place on behaviour of combustion under the effect of magnetic fields [1-4] providing the detailed study of the effects of gradient magnetic field on the diffusion flame emission, flame shape, luminosity and size, which are accepted as a result of the paramagnetic and diamagnetic properties of the flame species. The oscillation behaviour of laminar lifted flames under the influence of lowfrequency $\mathrm{AC}$ has been investigated experimentally in co-flow jets [5]. In this study possible mechanisms for the large-scale oscillation and the frequencydoubling behaviour have been discussed.

A strong dependency of the field induced reduction of pollutants on the diameter of the electrode has been found. With the optimized electrode configuration the electric power necessary to achieve a $\mathrm{CO}$ emission reduction of $90 \%$ was decreased by almost one order of magnitude. Moreover, an extended stability range was found and the overall lean blow off limit could be shifted by about $8 \%$ towards leaner operation. This enabled the combined reduction of $\mathrm{CO}$ and NOx emissions by about $60 \%$ and $40 \%$, respectively [6].

The effects of DC electric fields on the stability of downward propagating atmospheric pressure premixed propane-air flames that provide close coupling of the electric field to the flame have been carried out experimentally. The applied-electric fieldinduced modification of the thermo-diffusive effect could serve as a potentially attractive means of controlling flame fluid-mechanical characteristics and validating combustion instability models over a wide range of equivalence ratios [7]. Also, the chemical reaction rate, flow velocity, species mass fraction distribution, flame deformation, and flame temperature under the effect of DC electric field were studied. It was resulted in that the flame characteristics were changed by electric field mainly due to the body forces acting on charged particles in the electric field [18]

The stabilization characteristics of lift-off and blowoff in non-premixed laminar jet flames in a co-flow have been investigated experimentally for propane fuel by applying AC and DC electric fields to the fuel nozzle with a single-electrode configuration [8]. The results showed that the detachment velocity could be extended appreciably by applying the AC voltage to the central fuel nozzle. Also, the increase in the AC frequency improved the stabilization in the nozzleattached flame mode. The stabilization characteristics of laminar premixed Bunsen flames have been investigated experimentally by applying $\mathrm{AC}$ electric fields at low frequency below $60 \mathrm{~Hz}$ together with DC in the single electrode configuration $[9,16]$. The blow-off behaviour with DC showed that it decreased (increased) with positive (negative) DC, indicating the influence of the ionic wind on flame stabilization.

The promotion of combustion reactions in diffusion flames by inhomogeneous magnetic fields has been investigated [10]. The effects of pulsed and continuous DC electric fields on the reaction zones of premixed propane-air flames have been investigated experimentally [11]. All observed effects on the flame are dependent on the applied voltage polarity, indicating that negatively charged flame species do not play a role in the perturbation of the reaction zone.

Numerical simulation for combustion in the presence of an external electric field has been developed [12], for understanding the mechanisms of the electric field interaction with the flame. The sensitivity of the flame lift-off height to the applied voltage was studied and the modification of the velocity field ahead of the flame base induced by the electric volume forces was highlighted.

The effects of chemi-ion current induced flow perturbations in a premixed, laminar propane/air flame at atmospheric pressure have been measured with $30 \mathrm{~ms}$ wide applied pulsed voltages [13]. It was concluded that the applied electric field can cause an otherwise laminar flame to transition-to-turbulence regime as indicated by the widened flame brush reaction zone.

The effects of DC electric fields on non-premixed counter-flow flames with emphasis on flow modifications caused by a bidirectional ionic wind experimentally investigated [14]. It was found that the original flow field separates near the flame when it locates at a flow stagnation plane, resulting in a double stagnant flow configuration. The influence of the electric field on premixed turbulent jet flames at 
increased pressure was investigated [15]. The improvement of the lean blow-off limit upon application of an electric field was observed and increased with pressure. The effects of dilutions of $\mathrm{N}_{2}, \mathrm{CO}_{2}$ and $\mathrm{H}_{2} \mathrm{O}$ on temperature and fields of concentrations of $\mathrm{OH}$ in Benson flames of methane fuel were investigated [17].

Evidenced by survey that many of the previous researches have addressed the impact of electric field on the thermal and physical properties of different flame characteristics, but because of the disparities among results and the lack of research on studying the effect of electric field on the reaction zone thickness and the emissions resulting from the reaction and combustion, especially in a lean mixture region and flame stabilization, a deep and rigorous studies are required in this field. This is the motivation to start an integrated research program in laboratory of mechanical power engineering department, faculty of engineering, Menoufiya university to study all the parameters related to electric field and its effect on the characteristics of the types of flame (premixed or diffusion) either physical or thermal. Therefore, a laboratory experimental set up has been built up to carry out various experiments. This study explores the first part of this research program.

\section{EXPERIMENTAL SET-UP}

The focus of the current investigation is to study and elucidate experimentally the effect of electric field of moderate strength, $5 \mathrm{kV}$ on the physical, chemical, and thermal characteristics of laminar premixed flame. For doing so, the relation between electric field and thickness of reaction zone has to be studied clearly, beside the limits of flame stability especially at lean side. Therefore, series of experiments were carried out on laminar premixed flame (LPG/ Air mixture) in order to investigate the flame behaviour when exposed to electric field. Experimental test rig was designed and manufactured to facilitate separation of variables affecting the phenomenon under consideration. The following sections describe such test rig components along with the interaction between premixed flame and electric field, as schematically shown in fig.(1).

Figure (1) Shows the experimental test rig facility used in this study. The essential features of the set up are a burner, fuel and air supply systems, pressure regulators, $\mathrm{U}$ tube manometers and orifice meters, traverse system mechanism, and measuring instruments.

\section{TEMPERATURE MEASUREMENT}

Temperature measurements are critical to this study as they help to identify the electric field's effect on the combustion process occurring in the flame. They also provide a means of characterizing the flame structure, the zones of soot particle inception, growth and oxidation within the flame. Thus, the temperature was measured at various locations within the flame for a given flame configuration. The measurements were made at various radial and axial locations in the flames studied. The specific goal is to establish the temperature profiles characteristic of such flames and to study the impact of the electric field on the measured temperature distribution.

The thermocouple and traverse mechanism facilitates its vertical and horizontal movement for the axial and the radial measurements in the flame respectively. So, a digital read out thermocouple of the type (k) for measuring local flame temperatures is mounted on a two-dimensional traverse system mechanism coupled with a stepper motor that has an accuracy of $1 \mathrm{~mm}$ radially and axially, and controlled by Arduino system.

\section{BURNER}

As shown in fig.(2) burner was designed such that the air enters the mixing chamber tangentially which in turn provides high turbulence for mixing with fuel entering axially. This enhances the mixing of fuel and air, subsequently more homogeneous, efficient combustion and desirable combustion characteristics. The flow rates of both fuel and air are controlled and measured by pressure regulators, $U$ tube manometers, and orifice meters that calibrated so as to prepare the specified mixture with the required mixture strength. A mixture of $60 \%$ Propane $\left(\mathrm{C}_{3} \mathrm{H}_{8}\right)$ and $40 \%$ Butane $\left(\mathrm{C}_{4} \mathrm{H}_{10}\right)$ by volume respectively is supplied from pressurized gas cylinder. The fuel density at $1 \mathrm{~atm}$. and temperature of $30^{\circ}$ is $1.98 \mathrm{Kg} / \mathrm{m}^{3}$. The flowing air is supplied from a pressurized tank charged by a reciprocating compressor.

\section{PRESSURE REGULATORS}

For controlling the pressure of air and fuel before entering burner a two pressure regulators were used one for air and the other for fuel. Gas and air pressure regulators were used only to regulate and maintain the constancy of both air and fuel pressures during their flow.

\section{TRANSFORMER}

The potential difference of $5 \mathrm{kV}$ of alternating current is produced by electrical transformer which was fed to two electrodes oriented vertically and horizontally around the flame to create alternating electric field. 


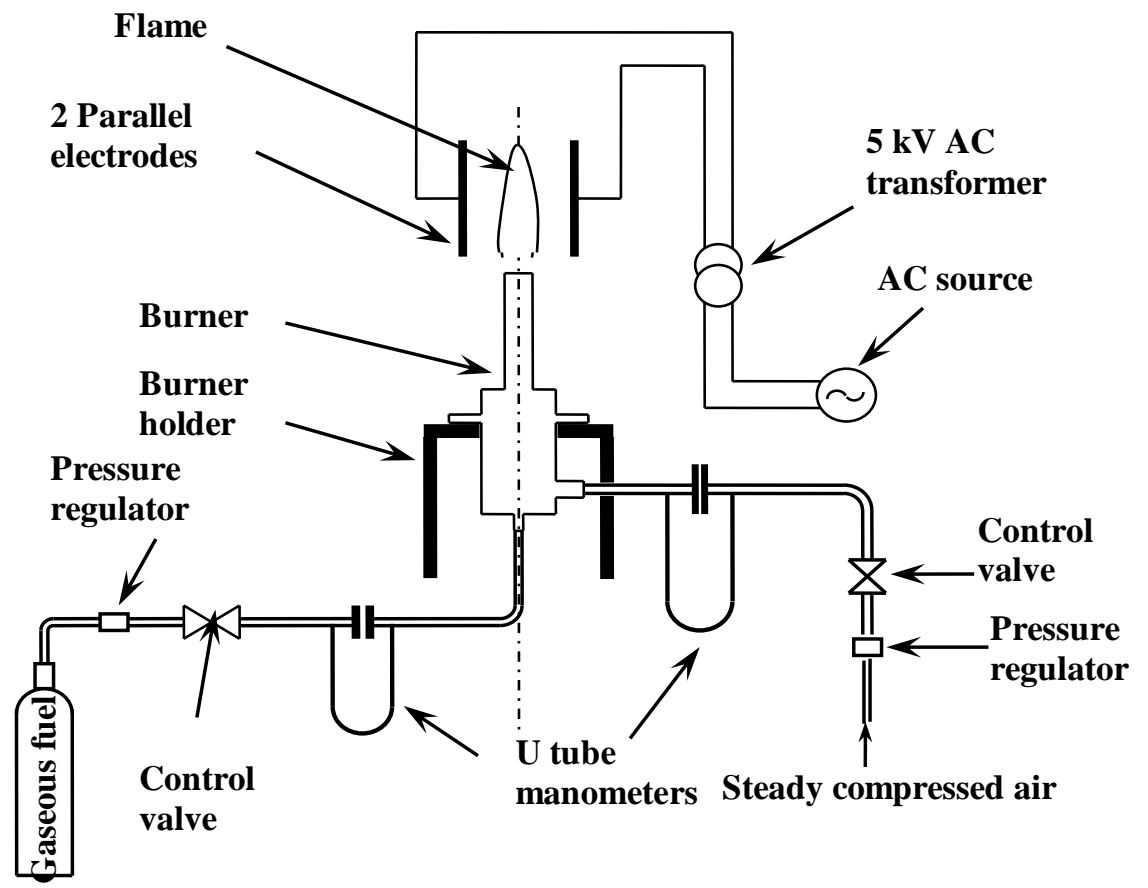

Figure (1) Layout of the Experimental Test Rig

\section{FLAME IMAGES - A VISUAL ANALYSIS}

Visual examination of combustion process at different operating conditions was carried out by using a digital camera and an analysis of the flame shapes and heights was performed. Observations such as the luminosity and the colour of the flames together with the flame structure and its height constitute the qualitative analysis.

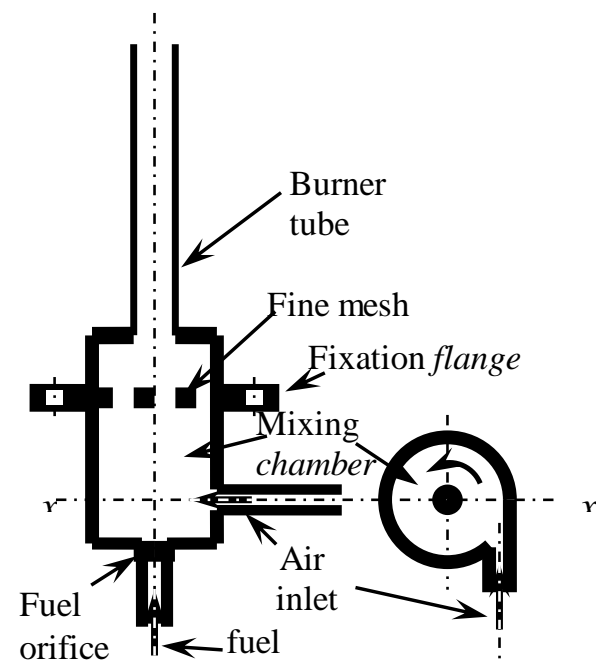

Figure (2) Details of Burner Design

\section{DIGITAL CAMERA}

In present experimental work, full frame $24 \times 36 \mathrm{~mm}$, DSLR camera was employed in order to capture the flame image with highest possible dynamic range. (Nikon D600, 24 MP, Lens (Sigma- macro 105 mm,
F2.8, frame rate of $5.5 \mathrm{fps}$, max shutter speed 0.25 ms) was used.

\section{UNCERTINTY ANALYSIS}

To ensure experimental repeatability for the measurements, each test was carried out three times and the averaged data were reported and employed to conduct the uncertainty analysis. Uncertainty of air flow rate and fuel flow rate measurements were estimated to be about $\pm 5 \%$ and $\pm 4 \%$ respectively. Temperature measurements uncertainty is within $\pm 0.1 \%$. Uncertainty of flame length measurements is $\pm 2.63 \%$.

\section{TEST CONDITIONS AND PROCEDURES}

The operating and geometrical conditions under which the experiments were carried out are shown in table (1). The mixture strength of fuel and air was changed by keeping the fuel mass flow rate constant at all the experiments and changing the air flow rate according to the specified mixture strength. At each experiment the temperature mapping throughout the flame was measured, as well as imaging the flame by digital camera. The same measurements were repeated with the same procedures but under exposing the flame to electric field with changing the orientation of two electrodes with respect to the flame. The electrodes were vertical around the flame with changing the gaps between them. On the other hand the effect of horizontal orientation of electrodes with respect to the flame was also investigated. 
Table (1) Operating and Geometrical Conditions

\begin{tabular}{|l|l|l|l|l|}
\hline \multicolumn{1}{|c|}{ Variable } & \multicolumn{3}{|c|}{ Changing values } \\
\hline Equivalence ratio & 1.4 & 1.19 & 1.03 & 0.91 \\
\hline $\begin{array}{l}\text { Vertical distances } \\
\text { between electrodes }(\mathrm{mm})\end{array}$ & \multicolumn{4}{|c|}{$\begin{array}{c}40,50,60,70,80,90,100 \\
(\mathrm{~mm})\end{array}$} \\
\hline $\begin{array}{l}\text { Horizontal distances } \\
\text { between electrodes }(\mathrm{mm})\end{array}$ & \multicolumn{3}{|c|}{$\begin{array}{c}40,60,70,80,90 \\
(\mathrm{~mm})\end{array}$} \\
\hline
\end{tabular}

RESULTS AND DISCUSSION

\section{PREMIXED FLAME CHARACTERISTICS WITHOUT ELECTRIC FIELD EFFECT}

\section{FLAME HEIGHT}

Flame height is the length of the flame from the burner rim to the maximum apparent height of flame. The relative flame height was found to be directly proportional to the equivalence ratio $(\phi)$ as shown in fig.(3a). As the equivalence ratio $(\phi)$ increases the relative flame height increases either the outer flame height (L) or the inner flame height (l) where relative outer flame height includes the diffusion and premixed region in the flame. This may be explained as the rich mixture i.e. $\phi>1$ leads to incomplete combustion due to deficiency of oxygen. Therefore, it leads to generate $\mathrm{CO}$ and $\mathrm{H}_{2}$ products which mix with surrounding atmospheric air and combust as diffusion flame (outer part). The richer is the mixture, the more is the generation of $\mathrm{CO}$ and $\mathrm{H}_{2}$ consequently the more length of flame. With regard to the inner part (premixed), the greater the richness of the mixture, the lower the flame temperature and the lower the flame speed and reaction rate that leads to the increase in inner flame length. Fig.(3b) shows a picture of flame including both the premixed and diffusion regions.

The inner flame height increases as the equivalence ratio $(\phi)$ increases as shown in fig. (4). Relative inner flame height $(1 / \mathrm{D})$ is defined as the ratio between the inner flame height (l) to the inner burner diameter (D) where $\mathrm{D}=14 \mathrm{~mm}$.

\section{REACTION ZONE}

\section{MEASURING REACTION ZONE THICKNESS}

Reaction zone is the playground for combustion process, where the most vital primary reactions occur. It characterized by highest rate of radical production which makes this zone illuminated, a condition which distinguishing it from other flame zones. Therefore, image processing technique is employed to explore and measure the depth of this zone. For this purpose, digital single lens reflex (SLR) camera equipped with full frame sensor was used. This type of sensor is capable to capture the image with highest possible dynamic range and consequently leads to isolate this zone with the aid of suitable software.

In order to obtain more sharp image with narrow depth of field, macro lens with $105 \mathrm{~mm}$ focal length was used at wide aperture (f 2.8). All flame structure dimensions illustrated in fig. (5-a). are measured via image processing as follows. At the beginning, linear scale for pixle size is assigned and therefore counting the number of illuminated pixles inside reaction zone enables to determine its thickness easily. Other flame dimensions are obtained as well. Based on present imaging technique and camera setting, each $1 \mathrm{~mm}$ contains 20 pixles which equivalent to $\pm 0.05 \mathrm{~mm}$ accuracy. In order to obtain representative image for inner premixed zone and to isolate the reaction zone, wide aperture (f3) and high shutter speed (1/2000 s) are setted up to capture the image with shallow depth of field as shown in fig. (5-b). Sensitivity of the sensor is raised to ISO 3200 in order to achieve the correct exposure depending on radiant flame light only. This is the reason for using full frame camera at which this level of high sensitivity cannot be achieved except in such type. The author believes that this a new technique used for measuring the flame reaction zone thickness.

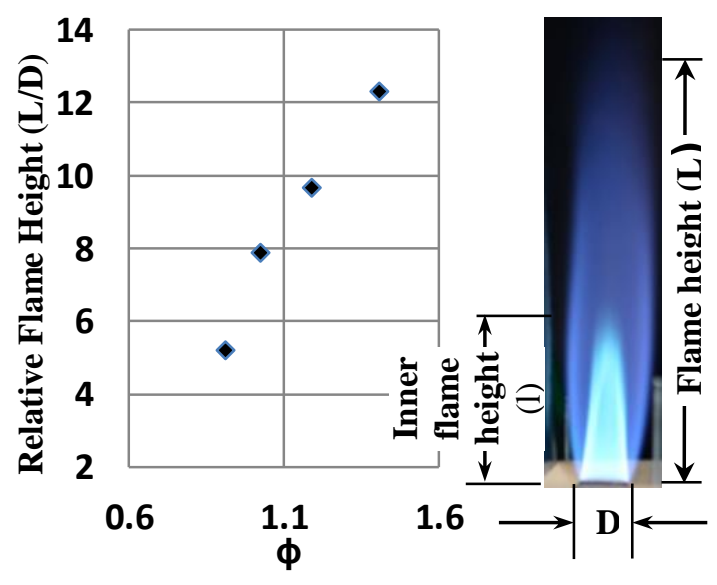

(a)

Figure (3)

(b)

(a) Relation between Relative Flame Height and Equivalence Ratio $\phi$

(b)Premixed and Diffusion Flame Regions

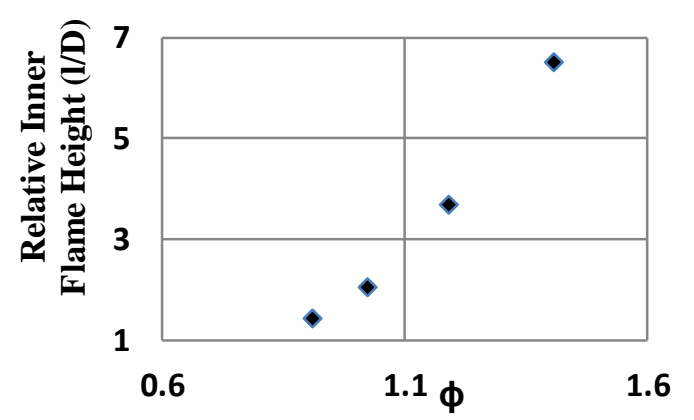

Figure (4) Relation between Relative Inner Flame 
Height and Equivalence Ratio $(\phi)$

The reaction zone is the region where the combustion of fuel and air takes place. There is a relation between this region and both of flame height and equivalence ratio. It was noticed that the reaction zone thickness is not constant along the flame length, but its thickness varies from the bottom to the tip of the flame. Actually thickness of this region increases along the flame height until reaching the tip of the inner cone height at this place the maximum reaction zone thickness takes place as shown in fig.(6). Figure (7) shows the average reaction thickness of the flame as a function of equivalence ratio. One can observe that maximum reaction zone thickness occurs at (equivalence ratio $\phi=1.03$ ) slightly rich.

PREMIXED FLAME CHARACTERISTICS UNDER THE EFFECT OF ELECTRIC FIELD

In this part of study the experiments were carried out on the flame exposed to $5 \mathrm{kV}$ AC through two vertical electrodes parallel to the flame axis. The gap between the two electrodes changes according to the values in table (1). Ambient pressure and temperature during experimental work were found to be 1.022 bar and $36^{\circ} \mathrm{c}$.

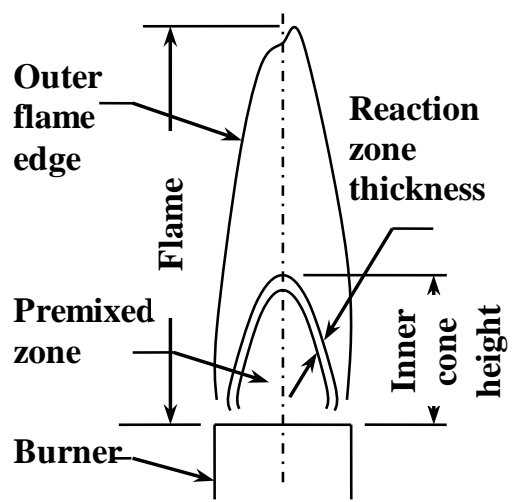

(a)

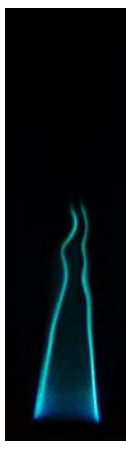

(b)
Figure (5) Premixed Flame Structure

\section{FLAME HEIGHT AND MAXIMUM WIDTH}

Figure (8) illustrates the effect of electric field on the length and maximum width of flame. It is clear that the flame height decreases and the flame width increases compared with the length and height of the flame without electric field which leads to more flame compactness. The percentage changes of both length and width of the flame due to the effect of electric are calculated according to the following equations:

$$
\begin{aligned}
& \text { percnt change in flame length } \% \\
& \qquad=\frac{l_{o}-l_{e}}{l_{0}} \times 100 \\
& \text { percnt change in flame width } \% \\
& =\frac{d_{e}-d_{o}}{d_{0}} \times 100
\end{aligned}
$$

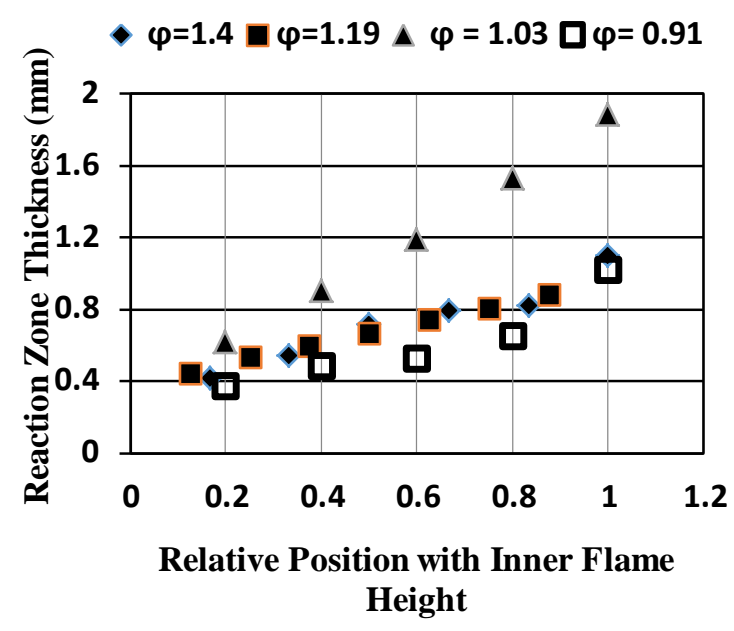

Figure (6) Reaction Zone Thickness

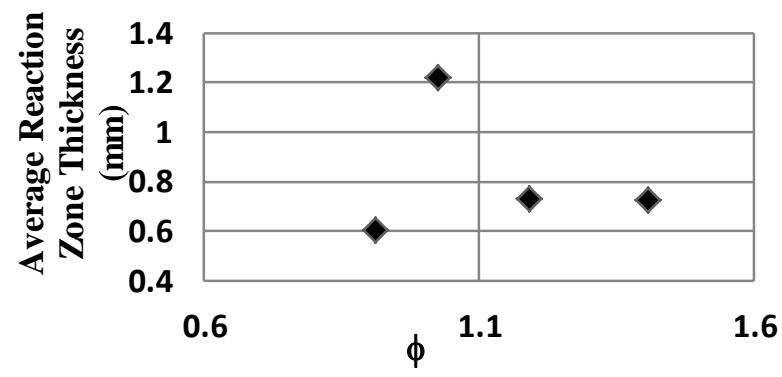

Figure (7) Average Flame Reaction Zone Thickness at Different $\phi$

Applying electric field on flame zone leads to produce what called bi-directional ionic wind (due to AC source). This ionic wind enhances the collision frequency of reactant molecules and consequently boosts the reaction rate. This may interpret the shortening in the flame length. On the other hand, electric field has significant effect on dielectric gases like carbon monoxide. It contributes to attract the charged molecules towards the electrodes perpendicular to the flame axis. This in turn leads to stretching the flame width.

\section{INNER FLAME HEIGHT (PREMIXED)}

The length of inner part of the flame (premixed) decreases under the effect of electric field compared with the length without the effect as shown in fig. (9). This is attributed to the improvement of reaction rate and the flame speed. It is also observed that the electric field is more effective in rich side of mixture strength than in lean side as well as the less effect occurs at equivalence ratio of 1.03. 
EFFECT OF GAP DISTANCE BETWEEN ELECTRODES ON INNER FLAME HEIGHT

The gap distance between the vertical plates was changed from $40-100 \mathrm{~mm}$ with step $10 \mathrm{~mm}$ each. The height of the inner flame (premixed) was measured at equivalence ratio of 1.19 as shown in fig. (10). It is noticed that at the gap distance of $70 \mathrm{~mm}$, the relative change in inner flame height is minimum but at gap distances greater than or less than this distance, the relative change in inner flame height increases with respect to the height of the flame under no electric field. This may be interpreted as follows; when the gap distances increases beyond certain critical limit, the intensity of electric field decreases and consequently, its effect on the flame becomes insignificant. Therefore, the flame tends to return to its original height. It was observed also, that, when the gap distance becomes shorter than this critical limit, the effect of electric field gives the same trend. The cause of this behaviour is not clear at the current moment and needs more work to explore it. In present work, the critical limit of electrodes gap was found to be $70 \mathrm{~mm}$ at equivalence ratio of 1.19 .

\section{EFFECT OF GAP DISTANCE ON FLAME HEIGHT AND MAXIMUM FLAME WIDTH}

Figure (11) shows the effect of gap distance on relative flame height and maximum flame width. It is clear that the minimum relative flame height occurs at $70 \mathrm{~mm}$ gap distance between the electrodes at the same time the maximum flame width obtained at the same gap distance. This is due to the stretching effect of electric field on the flame.

\section{EFFECT OF EQUIVALENCE RATIO ON REACTION ZONE THICKNESS}

The effect of electric field on the reaction zone thickness at different equivalence ratios is shown in fig. (12). It is clear that the reaction zone thickness increases with induced electric field at all equivalence ratios. It was found also that the difference in reaction zone thickness in the two cases increases towards the leaner mixture strength. This can be attributed to that the reduction of fuel molecules inside this domain leads to increase the permeability of electric field, consequently increases the momentum transferred to the reactant molecules. Therefore, the molecular diffusivity increases which leads to corresponding increase in reaction zone depth. This proves the importance of electric field in improving the flame stability for lean mixtures. It was also observed that applying electric field leads to increasing the width of premixed zone and decreasing its height slightly as shown in figure (13) $a$ and $b$.

\section{FLAME TEMPERATURE DISTRIBUTION UNDER THE EFFECT OF ELECTRIC FIELD}

Figure (14) shows the temperature contours throughout the flame with and without the effect of electric field at equivalence ratio of 1.03. This figure accentuates the increase of flame width under electric field as mentioned above.

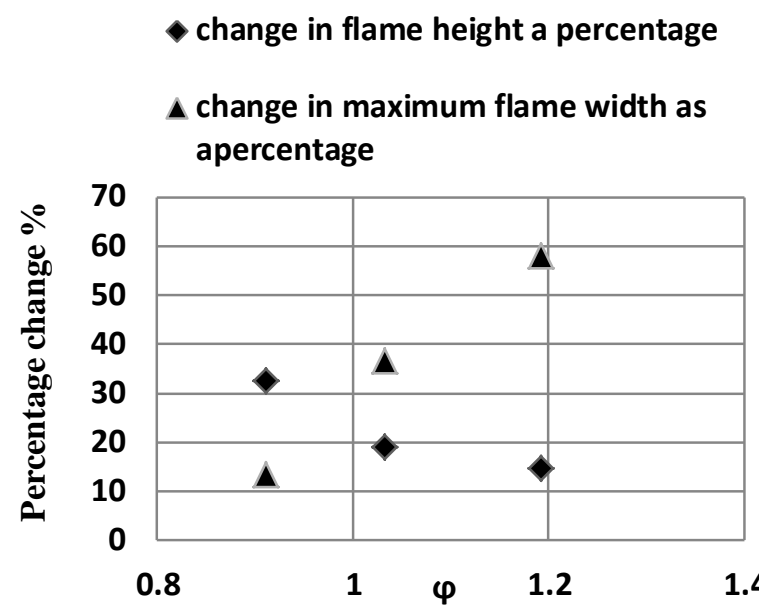

Figure (8) Effect of Electric Field on Flame Height and Width

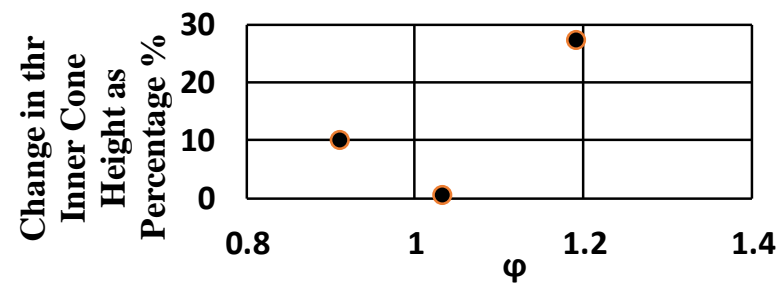

Figure (9) Effect of Electric Field on Inner Flame Height (Premixed)

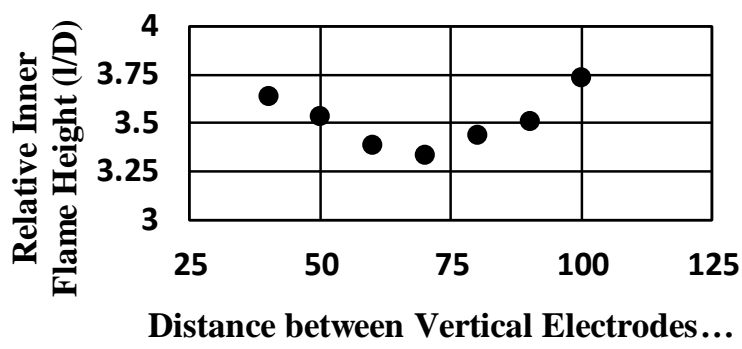

Figure (10) Effect of Gap Distance between Vertical Electrodes on Relative Inner Flame Height at $\phi=1.19$ 


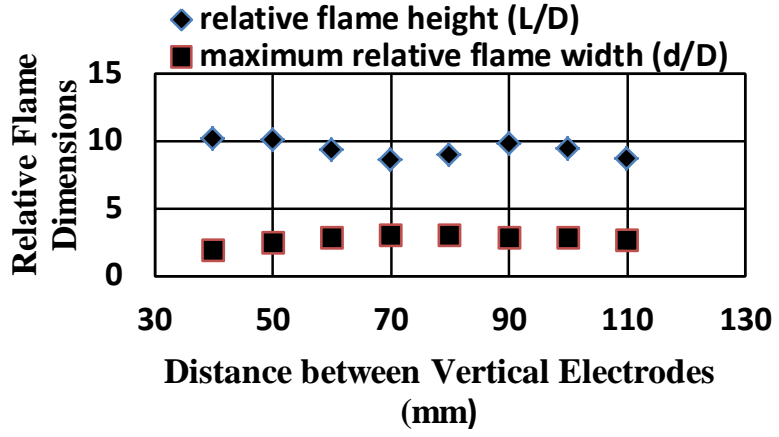

Figure (11) Effect of Gap Distance between Vertical Electrodes on Relative Flame height and Maximum Relative Width at $\phi=1.19$

จ reaction zone thickness without electrical effec reaction zone thickness with electrical effect

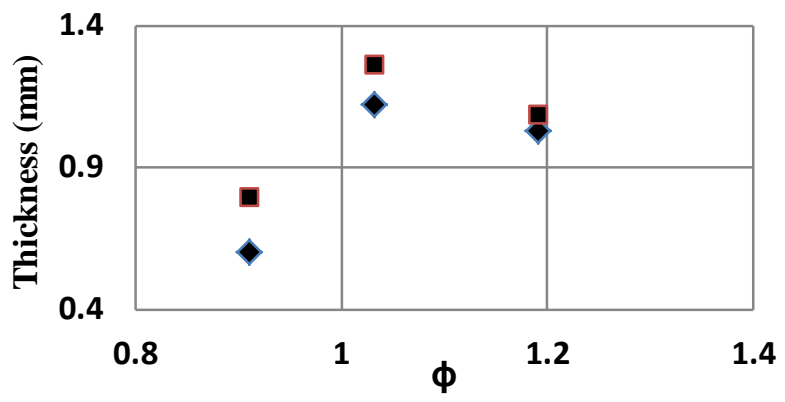

Figure (12) Reaction Zone Thickness
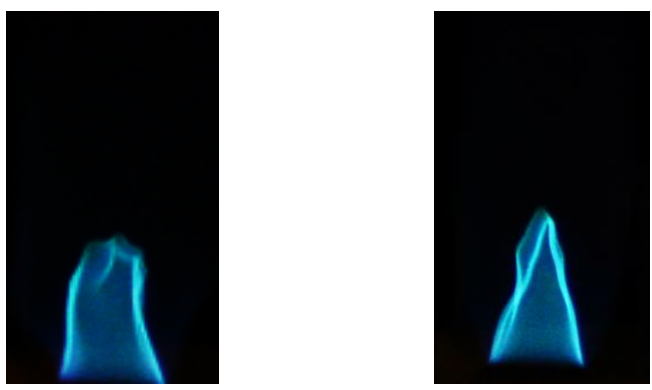

Reaction Zone Thickness with Electric Field

(a)

\section{Reaction zone Thickness without Electric Field}

(b)
Figure (13) Effect of Electric Field on Reaction Zone Thickness at the Same Equivalence Ratio $(\phi=0.91)$
EFFECT OF ELECTRIC FIELD ON FLAME STABILITY AT LEAN SIDE

When the flame was exposed to electric field, it was oscillated between vertical electrodes as the charge of alternating current changed quickly. In order to depict these oscillations, a high speed camera of more than $60 \mathrm{fps}$ is needed which was not available. However, the measurements have been taken to study how the flame would be stabilized and not extinguished, especially at lean side of mixture strength. It was found that the flame stayed stable until the mixture strength approached to 0.67 of equivalence ratio under the effect of electric field. This result was very important because this will help in increasing efficiency of fuel burning.

\section{FLAME TEMPERATURE UNDER ELECTRIC FIELD WITH HORIZONTAL ELECTRODES}

The recorded data reveal that the effect of horizontal electrodes was marginal on temperature inside the flame. Figure (15) shows the change of temperature at a single point for different equivalence ratios at different horizontal electrodes span. It is obvious that

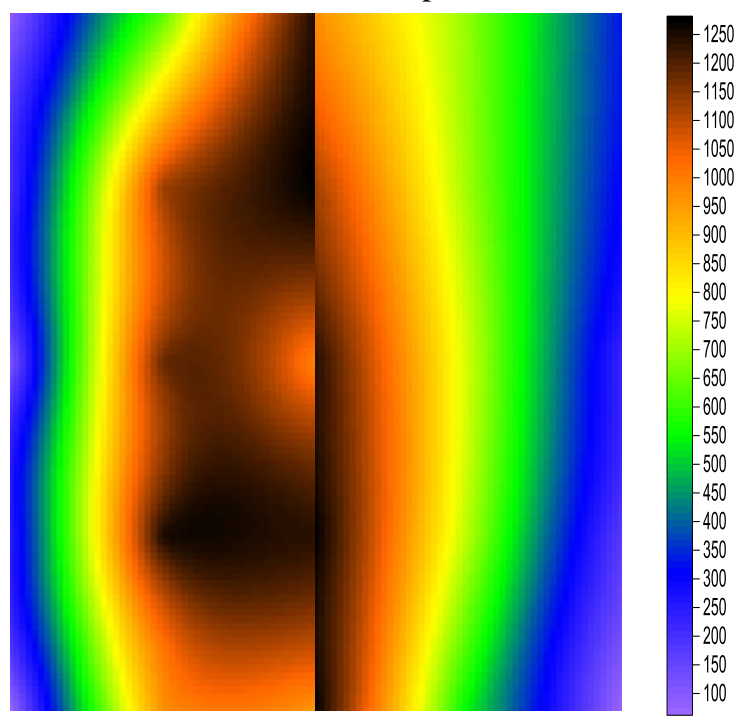

Temperature without Temperature with the Effect of Electric Field. the Effect of Electric Field.

Figure (14) Temperature Distribution across the Flame at $\phi=\mathbf{1 . 0 3}$

the high level of temperatures were founded at slightly rich mixture; also the variation of temperature was within $15{ }^{\circ} \mathrm{C}$ in the range of the different electrode span from 40 to $90 \mathrm{~mm}$ at different equivalence ratios. This means that the horizontal orientation of electrodes and distance between them has little effect on temperature inside the flame. 


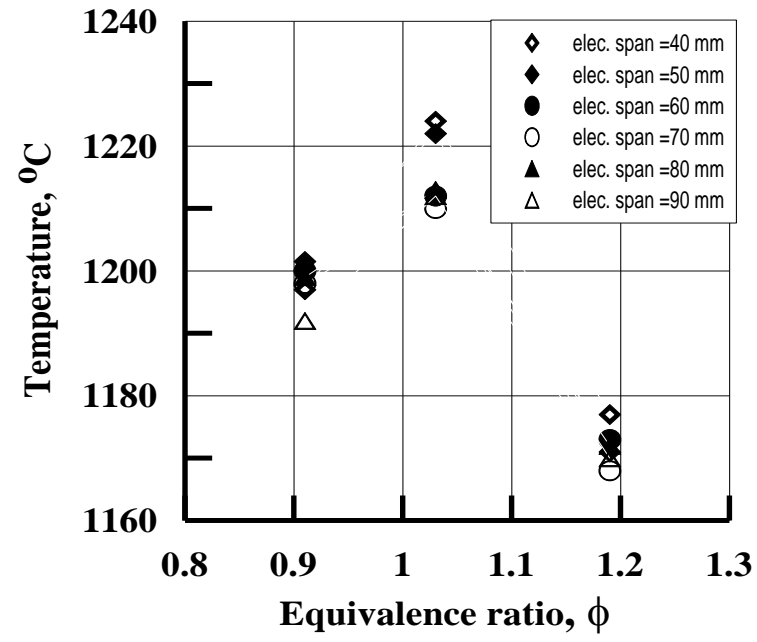

Figure (15) Temperature Change with Different Equivalence Ratios and Electrode Spans

\section{CONCLUTIONS}

The current study focused on the behaviour of premixed propane flame exposed to electric field. Therefore, experimental test rig was designed to facilitate the control and measure of basic flame parameters. Both equivalence ratio and electrodes span were varied separately. Electrodes orientation relative to flame axis was examined also. However, the results revealed that the horizontal electrodes position has trivial effect on the flame geometry. On the contrary, the vertical position of the electrodes has clear impact on the flame characteristics as shown in the results. Other results are summarized as follows.

1- The change in the inner cone height reaches its minimum point at $\phi \sim 1.03$ (slightly rich).

2- The change in temperature when the electric field is applied vertically or horizontally is marginal.

3- The important impact of electric field is increasing the reaction zone thickness and reaction rate that leads to increasing heat release rate.

4- Electric field makes flame stabilized until reaching a lean flammability limit of $(\phi=0.67)$ compared with $(\phi=0.74)$ at no electric field.

5- There's a significant change in the flame height with the effect of electric field as $\phi$ increases from lean to rich side.

6- The increase in maximum flame width is greater than the reduction in flame height with applying electric field.

\section{REFRENCES}

[1] Wakayama, N. I.: Magnetic Promotion of Combustion in Diffusion Flames. Physica B. National Institute of Advanced Industrial Science and Technology, Japan, Vol. 216, 1996, pp. 403405.

[2] Aoki, T.: Radicals' Emissions and Butane Diffusion Flames Exposed to Upward Decreasing Magnetic Fields. Japanese Journal of Applied Physics, Vol. 28, 1989, pp. 776-785.

[3] Baker, J., Calvert, M. E.: A Study of the Characteristics of Slotted Laminar Jet Diffusion Flames in the Presence of Non-uniform Magnetic Fields. Combustion and Flame, Elsevier, Vol. 133, 2003, pp. 345-357.

[4] Swaminathan, S.: Effects of Magnetic Field on Micro Flames. Thesis, Louisiana State University, USA, 2005, pp. 117.

[5] S.K. Ryu a, Y.K. Kim a, M.K. Kim a, S.H. Won a, S.H. Chung : "Observation of multi-scale oscillation of laminar lifted flames with lowfrequency AC electric fields" Combustion and Flame 157 (2010) 25-32.

[6] D. Most1, T. Hammer1, G. Lins1, D.W. Branston1, F. Altendorfner2, F. Beyrau2. "Electric Field Effects for Combustion Control Optimized Geometry" 28th ICPIG, July 15-20, 2007, Prague, Czech RepubliF.

[7] D.L. Wisman a, 1, S.D. Marcum a, B.N. Ganguly "Electrical control of the thermodiffusive instability in premixed propane-air flames" Combustion and Flame 151 (2007) 639-648

[8] M.K. Kim a, S.K. Ryu a, S.H. Won a, S.H. Chung "Electric fields effect on liftoff and blowoff of nonpremixed laminar jet flames in a coflow" Combustion and Flame 157 (2010) 17-24.

[9] Min Kuk Kim a, Suk Ho Chung. "Effect of electric fields on the stabilization of premixed laminar bunsen flames at low $\mathrm{AC}$ frequency: $\mathrm{Bi}-$ ionic wind effect" Combustion and Flame 159 (2012) 1151-1159.

[10] NOBUKO I. WAKAYAMA "Magnetic Promotion of Combustion in Diffusion Flames" Combustion and Flame 93:207-214 (1993).

[11] S.D. Marcum a, B.N. Ganguly "Electric-fieldinduced flame speed modification" Combustion and Flame 143 (2005) 27-36.

[12] Memdouh Belhi, Pascale Domingo, Pierre Vervisch "Direct numerical simulation of the effect of an electric field on flame stability" Combustion and Flame 157 (2010) 2286-2297.

[13] Jacob Schmidt a, Biswa Ganguly "Effect of pulsed, sub-breakdown applied electric field on propane/air flame through simultaneous OH/acetone PLIF" Combustion and Flame 160 (2013) 2820-2826. 
[14] Dae Geun Park, Suk Ho Chung, Min Suk Cha "Bidirectional ionic wind in nonpremixed counterflow flames with DC electric fields" Combustion and Flame 168 (2016) 138-146.

[15] A. Sakhrieh a, G. Lins b, F. Dinkelacker a, T. Hammer b, A. Leipertz. "The influence of pressure on the control of premixed turbulent flames using an electric field" Combustion and Flame 143 (2005) 313-322.

[16] M.K. Kim, S.H. Chung, H.H. Kim "Effect of AC electric fields on the stabilization of premixed Bunsen flames" Proceedings of the Combustion Institute 33 (2011) 1137-1144

[17] Zhen Yang, Xin Yu, Jiangbo Peng, Liyuan Wang, Zhiwei Dong, Xiaohui Li, Shaozeng Sun, Shun Meng, Huanhuan Xu "Effects of N2, CO2 and $\mathrm{H} 2 \mathrm{O}$ dilutions on temperature and concentration fields of $\mathrm{OH}$ in methane Bunsen flames by using PLIF thermometry and bidirectional PLIF" Experimental Thermal and Fluid Science 81 (2017) 209-222

[18] Yanlai Luo, Yunhua Gan, Xi Jiang "Investigation of the effect of DC electric field on a small ethanol diffusion flame" Fuel 188 (2017) 621-627 